\title{
3D Geometric Morphometrics Reveals Convergent Character Displacement in the Central European Contact Zone between Two Species of Hedgehogs (Genus Erinaceus)
}

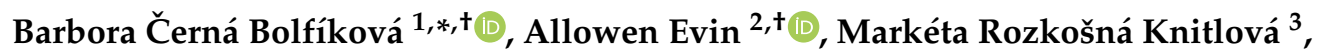 \\ Miroslava Loudová ${ }^{3}$, Anna Sztencel-Jabłonka ${ }^{4}$, Wiesław Bogdanowicz ${ }^{4}$ and Pavel Hulva ${ }^{3,5}$ \\ 1 Faculty of Tropical AgriSciences, Czech University of Life Sciences Prague, Kamýcká 129, \\ 16521 Prague, Czech Republic \\ 2 Institut des Sciences de l'Evolution-Montpellier (ISEM), Univ Montpellier, CNRS, EPHE, IRD, \\ 2 place Eugène Bataillon, CC065, CEDEX 5, 34095 Montpellier, France; allowen.evin@umontpellier.fr \\ 3 Department of Zoology, Faculty of Science, Charles University in Prague, Viničná 7, \\ 12800 Prague, Czech Republic; knitlova@natur.cuni.cz (M.R.K.); miroslava.loudova@natur.cuni.cz (M.L.); \\ hulva@natur.cuni.cz (P.H.) \\ 4 Museum and Institute of Zoology, Polish Academy of Sciences, Wilcza 64, 00-679 Warszawa, Poland; \\ brysio@miiz.waw.pl (A.S.-J.); wieslawb@miiz.waw.pl (W.B.) \\ 5 Faculty of Science, University of Ostrava, Chittussiho 10, 71000 Ostrava, Czech Republic \\ * Correspondence: bolfikova@ftz.czu.cz; Tel.: +420-22438-2497 \\ + These authors contributed equally.
}

Received: 25 August 2020; Accepted: 30 September 2020; Published: 4 October 2020

Simple Summary: Hedgehogs, being insectivores with slow metabolisms, are quite sensitive to temperature and food availability. As a consequence, their ranges have oscillated in relation to past climate changes. Species that have evolved in different regions, but their ranges have shifted and overlapped subsequently, often represent intense competitors as a result of ecological similarities. The present study focuses on this phenomenon in the contact zone in central Europe and adjacent regions, using genetic determination of species and description of size and shape of skull, the morphological structure mirroring many selection pressures related to ecology. While animals living outside of the contact zone show marked differences between the two species, individuals within the contact zone are more alike with a smaller skull size and a convergent jawbone shape. Changes in skull size can be related to inter-species competition and also facilitated by selection pressure, mediated by overpopulated medium-sized predators such as foxes or badgers. Since the function of the lower jaw is mainly connected to feeding, we hypothesize that this pattern is due to the selection to size and shape related to competition for food resources. The present study helps to describe general patterns related to species formation, as well as species responses to anthropogenic environmental changes.

Abstract: Hedgehogs, as medium-sized plantigrade insectivores with low basal metabolic rates and related defensive anti-predator strategies, are quite sensitive to temperature and ecosystem productivity. Their ranges therefore changed dramatically due to Pleistocene climate oscillations, resulting in allopatric speciation and the subsequent formation of secondary contact zones. Such interactions between closely related species are known to generate strong evolutionary forces responsible for niche differentiation. In this connection, here, we detail the results of research on the phenotypic evolution in the two species of hedgehog present in central Europe, as based on genetics and geometric morphometrics in samples along a longitudinal transect that includes the contact zone between the species. While in allopatry, Erinaceus europaeus is found to have a larger skull than E. roumanicus and distinct cranial and mandibular shapes; the members of the two species 
in sympatry are smaller and more similar to each other, with a convergent shape of the mandible. The relevant data fail to reveal any major role for either hybridisation or clinal variation. We, therefore, hypothesise that competitive pressure exerted on the studied species does not generate divergent selection sufficient for divergent character displacement to evolve, instead giving rise to convergent selection in the face of resource limitation in the direction of smaller skull size. Considering the multi-factorial constraints present in the relevant adaptive landscape, reduction in size could also be facilitated by predator pressure in ecosystems characterised by mesopredator release and other anthropogenic factors. As the function of the animals' lower jaw is mainly connected with feeding (in contrast to the cranium whose functions are obviously more complex), we interpret the similarity in shape as reflecting local adaptations to overlapping dietary resources in the two species and hence as convergent character displacement.

Keywords: convergent character displacement; Erinaceus; geometric morphometrics; species interactions

\section{Introduction}

Hedgehogs from the Western Palearctic play a key role as model organisms in the field of phylogeography and speciation studies (e.g., [1-3]). As medium-sized insectivores, they are sensitive to temperature and thus, to the productivity of ecosystems, to the extent that their ranges changed substantially during the Pleistocene climatic oscillations [2]. Indeed, isolation in southern refugia facilitated allopatric speciation scenarios, resulting in a recent pattern of east-west parapatry, with the northern white-breasted hedgehog (Erinaceus roumanicus) present in eastern Europe, and the European hedgehog (E. europaeus) occurring in western Europe. The two species form a secondary contact zone in central Europe (Italy, Austria, Czech Republic and Poland), with a relatively broad area of sympatry in the center of the zone (Czech Republic), possibly in relation to Neolithic deforestation [3]. This region therefore provides conditions suitable for studying species interactions in relation to genomic and ecological niche-differentiation in the context of anthropogenic environmental changes.

There has been little gene flow between E. europaeus and E. roumanicus [3-5]. Alongside genetic differentiation, there is a divergence of phenotypic traits in the closely related species which is an important source of information about adaptive processes, i.a. indicating nascent niche diversification [6]. In general, phenotypes respond to both abiotic and biotic factors. In sympatry, environmental factors are identical, but ecological, microallopatric or trophic differentiation may occur [7]. The integration of originating species into ecological networks also varies during the speciation process, in line with an increasing role for competition with the sister species that may facilitate the niche differentiation [8].

However, phenotypic variation in species with extensive ranges usually shows pronounced geographical variation, which complicates the comparison of allopatric populations. For example, the body size of E. roumanicus increases linearly from north to south in Europe and is thus shown to correlate positively with temperature, as well as negatively with precipitation in the summer [9]. It is hypothesised that size is in this case determined by seasonality of the resource availability [9].

Comparisons between the two species in allopatry thus tend to be lacking, given the requirement of sampling across the entire range, and/or controlled design of the study and homologous comparison, as regards environmental impact. Reeve [10] states that the species are of approximately the same size and weight, while comparisons between populations from Great Britain, Italy, Switzerland, Germany, Poland, Russia and Ukraine by Ruprecht [11] failed to find a key character allowing the species to be distinguished. The above author only sums up that "the western species is more differentiated in skull dimensions than the eastern species". Phenotypic differences between the white-breasted and European hedgehogs by reference to traditional morphometrics, or non-metric, discrete characters in the cranial phenotype prove relatively difficult. Hedgehogs are traditionally distinguished by cranial indices and the length of naso-maxillary sutures [12-14]; these characters in fact show marked 
intraspecific variability and interspecific overlap. Equally, sexual dimorphism related to size has never been found in either E. roumanicus or E. europaeus $[15,16]$.

In sympatry, E. europaeus has a higher mean body mass, mean body length, mean hindfoot length and mean ear length than E. roumanicus in all adult age classes, as well as higher values for cranial indexes $[15,17,18]$. Erinaceus roumanicus has a longer tail in adult categories [17]. Body mass and neurocranial capacity in turn increase at a higher rate in E. roumanicus $[17,19]$. Deciduous dentition is replaced earlier in E. roumanicus than in E. europaeus, while also showing fewer deviations from the normal dental formula [20].

The objective of this research was to compare phenotypic differences in allopatric and sympatric populations of the above-mentioned species in terms of size and shape of their skulls, by reference to geometric morphometrics and genetic determination of species. The skull, as a complex morphological structure integrating traits associated with cognitive, sensory and food-processing functions, reflects the diverse selection pressures associated with the ecological niche [6,21]. In order to eliminate the effect of environmental adaptation (position in relation to the north-south and oceanic-continental gradients), we used longitudinal transect sampling spatially crossing the relatively bounded region in central Europe. We expect that the unified environmental context will allow us to describe in detail the interspecific differentiation, resulting from the speciation process. We hypothesise that sympatric populations will be affected by character displacement. We aim to discuss the observed patterns also in the perspective of environmental changes of the Anthropocene.

\section{Materials and Methods}

\subsection{Specimens}

Only adult specimens were used in our analyses, the age was estimated based on the date of death, dental abrasion [22], presence of milk teeth [20] and skull proportions [15,17]. A total of 69 skulls were examined (Table S1 in Supplementary Material), 29 of them represented E. europaeus, 25 E. roumanicus and 15 interspecific hybrids. The specimens originated from different localities (Figure 1) within the zone of sympatry (Czech Republic-14 E. europaeus, 13 E. roumanicus) and from allopatric localities in central Europe (Germany-15 E. europaeus, Slovakia-12 E. roumanicus). Samples from areas of sympatry were obtained from individuals that died in rescue centers. Skulls from areas of allopatry were borrowed from the Museum für Naturkunde, Berlin (Germany; MFN) and the Institute of Vertebrate Biology, Brno (Czech Republic; IVB). The skulls of interspecific hybrids deposited at MFN have also been examined. Seven such specimens originated from hybridisation experiments carried out in captivity by Herter [23], while eight hybrids were collected from the wild (w-hybrid) in Germany and the Czech Republic. Hybrid individuals show morphological traits of both species regarding classical morphometric indices as mentioned above [23].

\subsection{Genetic Analyses}

Considering the low frequency of interspecific hybridisation (one backcrossed individual out of 210 tested in Czechia and Slovakia) [3,4], species determination based on phenotypes has been confirmed by sequencing the mitochondrial control region in the samples originating from the zone of sympatry $(\mathrm{N}=27)$. The tissue was collected in the course of skull preparation, and fixed in $96 \%$ ethanol, prior to storage at $-20^{\circ} \mathrm{C}$. DNA was extracted using a DNA Blood and Tissue Kit (Qiagen, Prague, Czech Republic). Amplification of the mtDNA control region was achieved in line with the protocol used in Bolfíková and Hulva [3]. Sequences obtained were compared with those available in the GenBank ${ }^{\circledR}$ database. 


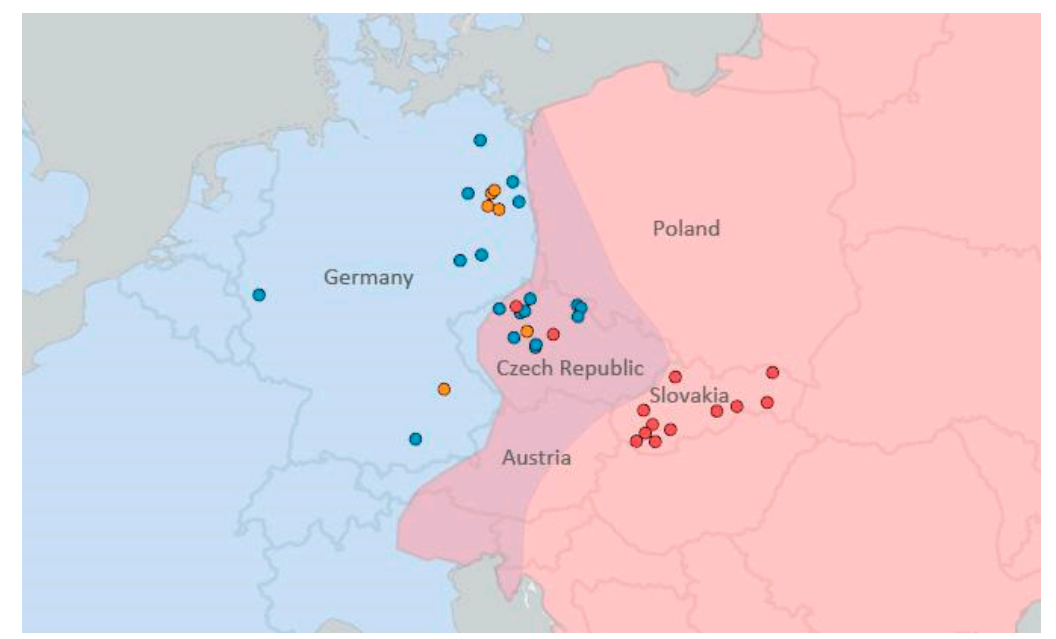

Figure 1. Species ranges and localities of samples used in the present study. The species are marked in different colours: blue represents E. europaeus, red represents E. roumanicus and orange indicates wild hybrids of the two species. The contact zone position (based on available data) is highlighted in violet. The map was created using ArcGIS Online.

\subsection{D Geometric Morphometrics Approach and Statistical Analyses}

Skull sizes and shapes were assessed using three-dimensional landmark-based geometric morphometrics. A total of 47 three-dimensional coordinates were recorded corresponding to 13 landmarks on the mandible, and 34 landmarks on the cranium divided into 13 and 21 landmarks on the ventral and dorsal side, respectively (Figure 2, Table S2). Landmark coordinates were acquired using the Reflex microscope and Axel software (Reflex Measurement Ltd., Butleigh, Somerset BA6 8SP, UK) at the Museum and Institute of Zoology of the Polish Academy of Sciences with headquarters in Warsaw. All measurements were taken by the same person (MK).

The coordinates were superimposed using a generalised Procrustes analysis algorithm [24,25]. During this procedure, all specimens are translated, so the center of gravity of their landmark configuration coincides, normalised to the unit centroid size and rotated to minimise the squared summed distances between corresponding landmarks. Centroid size (CS) corresponds to the square root of the sum of squared distances of the landmarks from their centroid [26]. The coordinates after superimposition correspond to the shape data.

Differences in the logarithm of CS between groups were depicted using a boxplot. Because of the small number of specimens in some of the comparisons, significance of the between-group differences was tested using the non-parametric Wilcoxon rank tests for two groups, and the Kruskal-Wallis tests when more than two groups were compared. Shape differences were tested using one-way multivariate analysis of variance (MANOVA) and canonical variate analyses (CVA) in combination with leave-one-out cross validation percentages (CVP), following Evin et al. [27], taking into account the unbalanced sample size between groups. Mean CVP values are provided with a $90 \%$ confidence interval obtained with 100 resamples [27]. Shape changes along the CVA axes were visualised by calculating shape changes along the factorial axes using multivariate regression [28] using the 'Morpho v2.8' $\mathrm{R}$ package [29]. Because sample sizes were relatively small compared to the large number of variables, we applied dimensionality reduction of the data prior to MANOVAs and CVAs by substitution of the primary data by the first scores of the principal component analyses (PCA) maximizing the leave-one-out cross validation between groups $[27,30]$. 


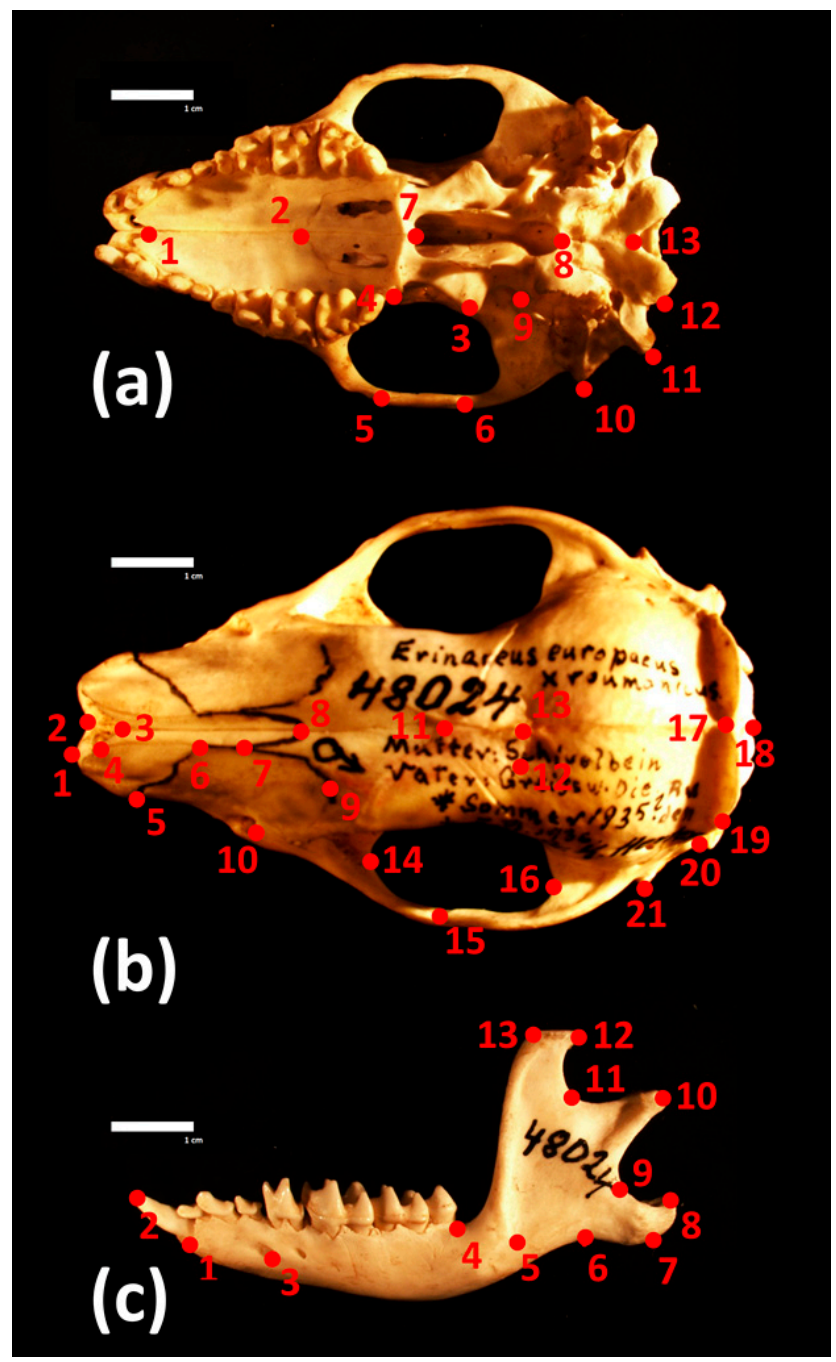

Figure 2. Location of the three-dimensional landmarks measured on (a) ventral and (b) dorsal sides of the cranium, and (c) the mandible.

To test for possible common differences in size and shape between allopatric and sympatric populations of the two species, we applied two-way ANOVA and MANOVA using size or shape as variables, species as the main classifier, and allopatric versus sympatric distribution as a sub-classifier factor. When necessary, $p$-values were adjusted for multiple comparisons after Benjamini and Hochberg [31]. Overall phenotypic similarities between groups were depicted using neighbour-joining networks, computed based on the Mahalanobis $D^{2}$ distances [32]. When allopatric and sympatric populations of the two species were compared, CVP were calculated for the main branches of the resulting neighbour-joining networks. The relationship between phenotypic data and geographic origin (latitude and longitude) was explored using the Mantel-test [33] for shape (Procrustes distances were used, and a randomized approach with 999 replicates), and regression [34] for centroid size for each structure and each species separately. To test whether the observed patterns of similarity can be explained by convergence [35], we adopted measures of the multidimensional convergence index (MCI) [36] calculated as the ratio of the Procrustes variance [37] within the putatively convergent lineages (i.e., sympatric populations) and within their sister lineages (i.e., allopatric populations). The obtained MCI values were compared to the distribution of 999 randomised MCI values (allopatric/sympatric attribution was randomised). Analyses were performed using the geomorph v3.2.0 [38] and ade4 v1.7.13 [39] for packages for R v3.6.3 [40]. 


\section{Results}

\subsection{Differences between the Species}

Morphologically related visual determinations of the species proved consistent with genetic assignment of animals within the sympatric population. On average, specimens of E. europaeus have a larger ventral side to the cranium and mandibles than those of E. roumanicus (Figure 3, Table 1), as well as a distinct cranial and mandibular shape (Table 1, Figure 4). When sympatric and allopatric populations are analysed jointly, 89.0\% (CI: 86-92\%), 94.8\% (CI: 90-98\%) and 84.0\% (CI: 80-90\%) of ventral, dorsal and mandibular shapes support the correct assignment of individuals to species (Table 1, Figure 4). If size alone is taken into account, the levels of correct cross-validation will drop respectively to $85.5 \%$ (CI: $84-88 \%$ ), $78.2 \%$ (CI: 72-82\%), and 72.7\% (CI: 70-74\%) (Table 1).

In terms of shape differences, E. roumanicus differs from E. europaeus in possessing a ventral size of the brain case that is proportionally more rounded (Figure S1a), as well as a dorsal side of the skull that is proportionally narrower (Figure S1b), and a mandible that is proportionally thinner, with the most anterior part shifted backward (Figure S1c).

\subsection{Contrasted Species Differentiation in Allopatry and Sympatry}

When allopatric and sympatric populations are analysed separately, as opposed to via pooled analysis, the results are seen to differ. In allopatry, the species exhibit significant differences in sizes and shapes of crania and mandibles (Table 1), to the extent that the minimal mean cross-validation between them is of $84.2 \%$ for the size of the dorsal side of the cranium (Table 1). Erinaceus roumanicus shows a smaller skull size than E. europaeus in all comparisons (Figure 3).

Table 1. Test of differences between species: overall (pooling sympatric and allopatric specimens) and separately sympatric or allopatric populations only. Differences in shape and size were tested using one-way multivariate analysis of variance (MANOVA) and Wilcoxon's tests, respectively, for ventral and dorsal sides of the cranium and the mandible. P: $p$-value, numDf and denDf: Numerator and denominator degrees of freedom, W: statistic of the Wilcoxon's tests. The numerator degree of freedom corresponds to the number of Principal Component (PC) scores included in the analyses. Cross-validation percentages (CVP) are provided as the mean and the $90 \%$ confidence interval of the distribution.

\begin{tabular}{|c|c|c|c|c|c|c|c|}
\hline \multirow{2}{*}{ Trait } & & \multicolumn{3}{|c|}{ Shape } & \multicolumn{3}{|c|}{ Size } \\
\hline & & F(numDf, denDf) & $p$ & CVP & $\mathbf{W}$ & $p$ & CVP \\
\hline \multirow{3}{*}{ Mandible } & Overall & $F(22,30)=5.94$ & $5 \times 10^{-6}$ & $\begin{array}{c}83.3 \% \\
(80-88.1 \%)\end{array}$ & 16.648 & $4 \times 10^{-5}$ & $\begin{array}{c}72.5 \% \\
(70-76 \%)\end{array}$ \\
\hline & Sympatry & $\mathrm{F}(15,10)=2.16$ & 0.11 & 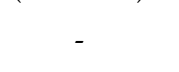 & 134 & 0.01 & $\begin{array}{c}69.2 \% \\
(69.2-69.2 \%)\end{array}$ \\
\hline & Allopatry & $F(13,13)=11.4$ & $4 \times 10^{-5}$ & $\begin{array}{c}89.8 \% \\
(79-95.8 \%)\end{array}$ & 164 & $1 \times 10^{-4}$ & $\begin{array}{c}85.7 \% \\
(79-87.7 \%)\end{array}$ \\
\hline \multirow{3}{*}{ Ventral } & Overall & $F(23,27)=8.68$ & $2 \times 10^{-7}$ & $\begin{array}{c}88.7 \% \\
(84-92.1 \%)\end{array}$ & 25.12 & $5 \times 10^{-7}$ & $\begin{array}{c}85.3 \% \\
(84-88 \%)\end{array}$ \\
\hline & Sympatry & $\mathrm{F}(19,5)=4.47$ & 0.05 & - & 133 & 0.04 & $\begin{array}{c}66.6 \% \\
(61.5-69.2 \%)\end{array}$ \\
\hline & Allopatry & $F(10,15)=7.32$ & $3 \times 10^{-4}$ & $\begin{array}{c}92.3 \% \\
(91.7-95.8 \%) \\
\end{array}$ & 155 & $7 \times 10^{-5}$ & $\begin{array}{c}92.2 \% \\
(91.7-95.8 \%)\end{array}$ \\
\hline \multirow{3}{*}{ Dorsal } & Overall & $F(29,24)=12.41$ & $1 \times 10^{-8}$ & $\begin{array}{c}95.0 \% \\
(92-98 \%)\end{array}$ & 15.713 & $7 \times 10^{-5}$ & $\begin{array}{c}78.2 \% \\
(72-82 \%)\end{array}$ \\
\hline & Sympatry & $\mathrm{F}(19,7)=17$ & $4 \times 10^{-4}$ & $\begin{array}{c}90.8 \% \\
(84.6-100 \%)\end{array}$ & 145 & $7 \times 10^{-5}$ & $\begin{array}{c}79.5 \% \\
(79.2-83.3 \%)\end{array}$ \\
\hline & Allopatry & $\mathrm{F}(15,11)=6.6$ & $1 \times 10^{-3}$ & $\begin{array}{c}84.25 \% \\
(83.3-87.5 \%)\end{array}$ & 167 & $4 \times 10^{-5}$ & $\begin{array}{c}84.7 \% \\
(83.3-87.5 \%)\end{array}$ \\
\hline
\end{tabular}

In relation to both size and shape, mean cross-validation percentages for the sympatric populations are always lower than those obtained in allopatry (Table 1). The sympatric populations of E. europaeus 
and E. roumanicus only differ significantly in dorsal skull shape, as well as the size of the mandibular and ventral skull view, with E. roumanicus characterised by smaller ventral size (Figure 3).
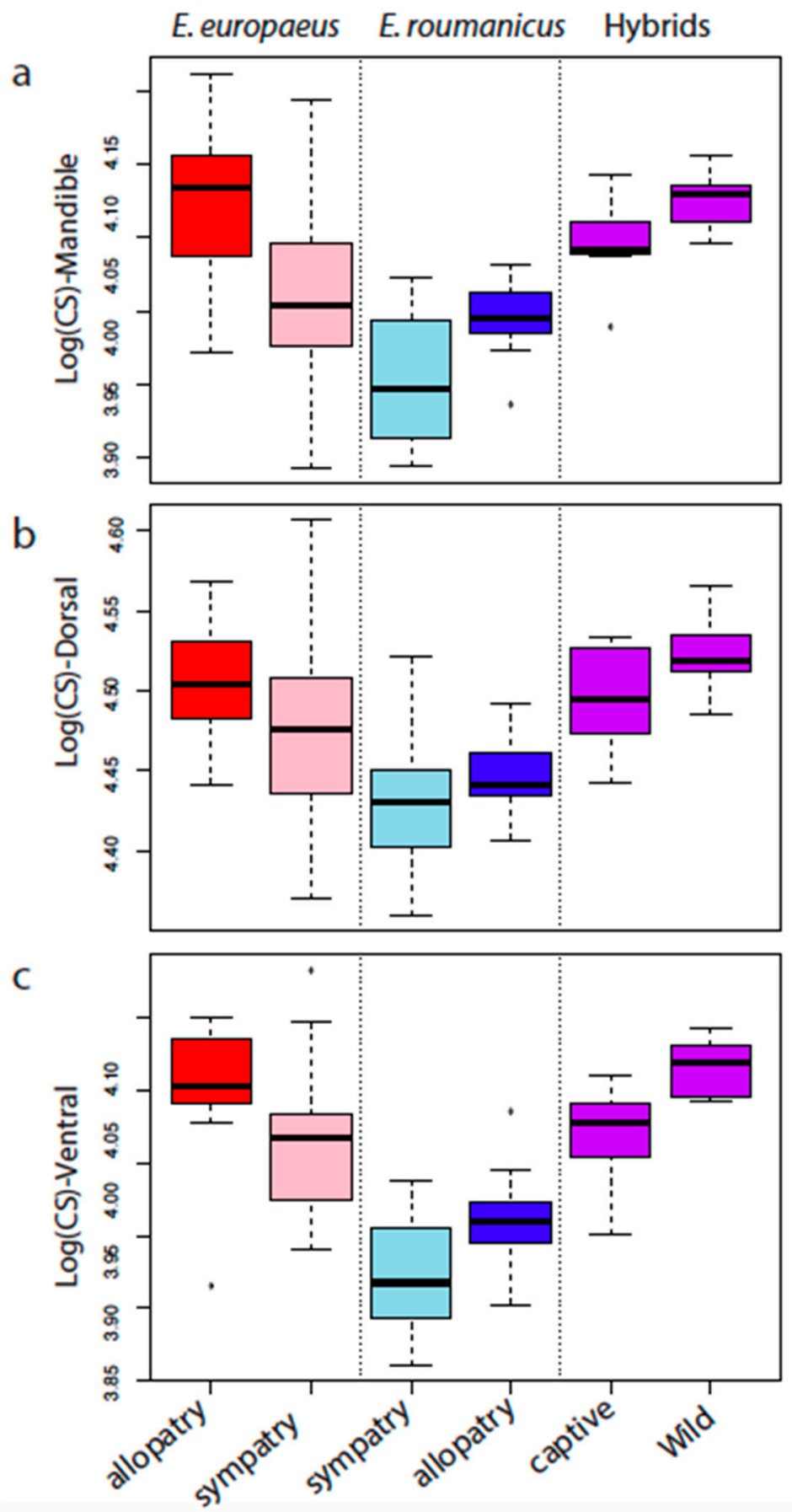

Figure 3. Cranial and mandibular size differences and variability between allopatric, sympatric and hybrid (captive and wild) populations of E. europaeus and E. roumanicus. Boxplots of the log centroid sizes (CS) of the mandible (a), dorsal (b) and ventral (c) sides of the cranium. 


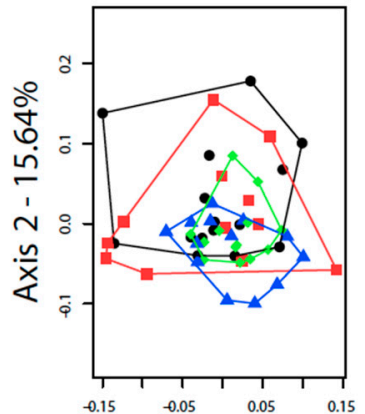

Axis $1-18.09 \%$

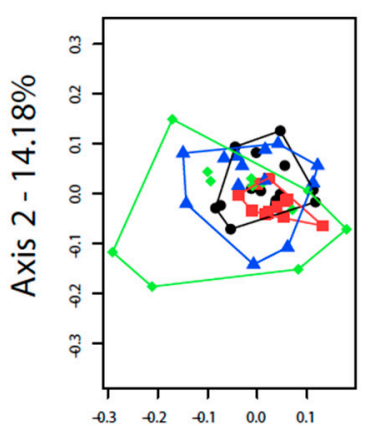

Axis $1-24.06 \%$

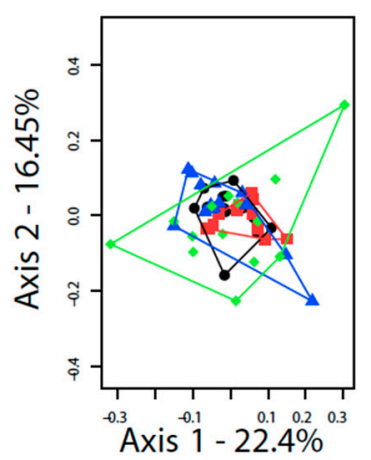

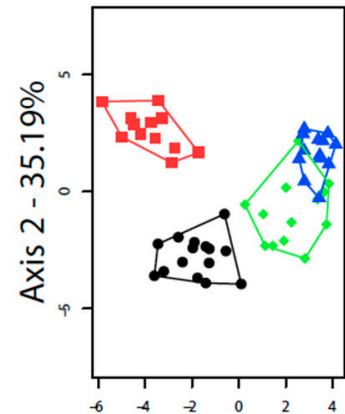

Axis $1-62.18 \%$

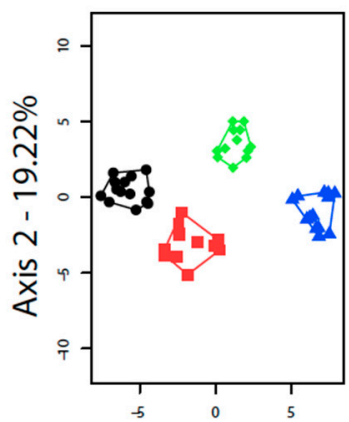

Axis $1-77.26 \%$
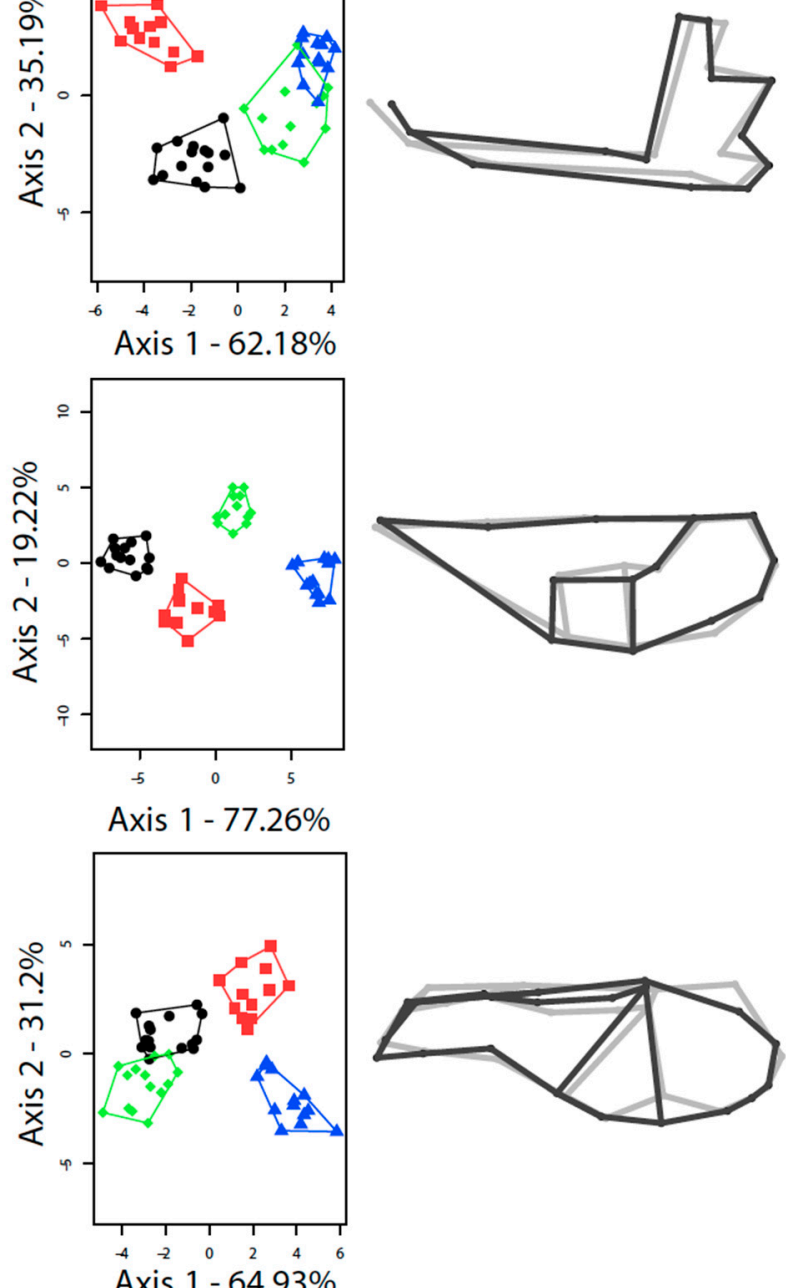

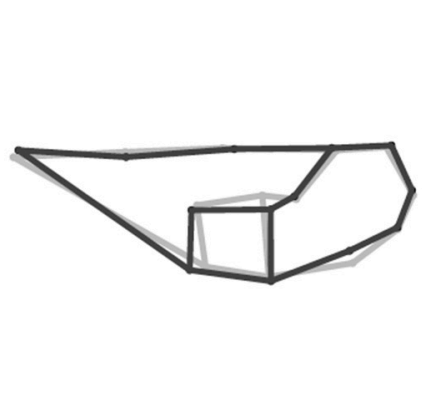

Figure 4. Principal component analysis (PCA; left section), discriminant analysis (DA; central section) and visualisation of the differences in shape between the two species (right section) in relation to mandible (top), ventral side (middle) and dorsal side (bottom). For PCA and DA, black stands for E. europaeus in allopatry, green for E. europaeus in sympatry, red for E. roumanicus in allopatry, blue for E. roumanicus in sympatry. For shape comparison, black stands for E. roumanicus and grey for E. europaeus; shape differences are amplified by a factor of 5 .

\subsection{Comparison of Allopatric and Sympatric Populations}

Both species are of smaller size in sympatry (Figure 3), with a further effect being that the two are also more similar in size than they are in allopatry. CVA analyses thus reveal marked differences between allopatric and sympatric populations, as well as between the two species (Figure S1).

The overall phenotypic dissimilarity between the populations (Figure 5) shows a greater similarity between the sympatric populations of the two species than between the two (sympatric and allopatric) populations of the same species, when it comes to the ventral side of the cranium and the mandible (Figure $\left.5 \mathrm{a}^{\prime}, \mathrm{c}^{\prime}\right)$. In the case of these two structures, morphometric differentiation is more affected by allopatric/sympatric status than by taxonomy. Conversely, for the dorsal side of the cranium (Figure $5 b^{\prime}$ ), the main differentiation is between the two species. The interaction term of the two-way analyses of variance reveals homogeneous patterns of differentiation between allopatric and sympatric populations of the two species (size and shape, all $p>0.5$; Figure 5), with the one exception relating to mandible shape $\left(F_{14,49}=3.27, p<0.01\right)$. 

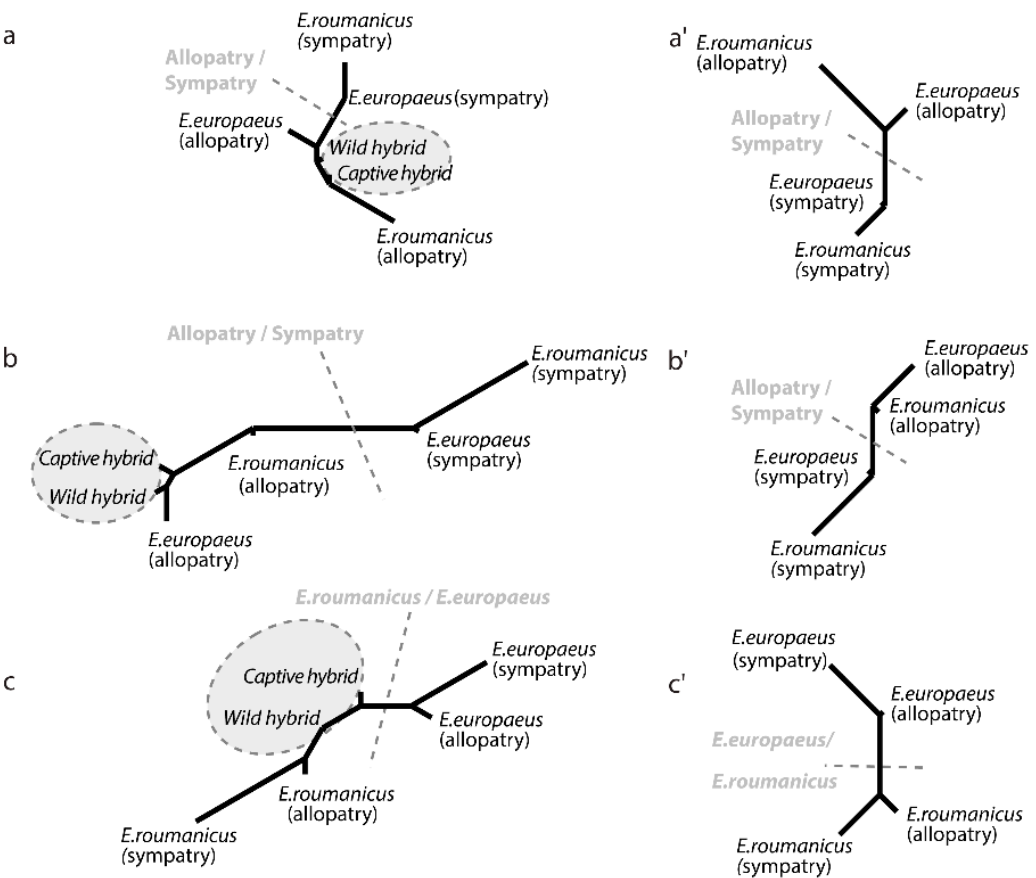

Figure 5. Overall shape differences among examined groups of E. europaeus and E. roumanicus: Right-between sympatric and allopatric populations of the two species; left-among all groups (allopatric, sympatric and hybrid populations). Neighbour-joining networks of the Mahalanobis distances for the mandible $\left(\mathbf{a}, \mathbf{a}^{\prime}\right)$, and the ventral $\left(\mathbf{b}, \mathbf{b}^{\prime}\right)$ and dorsal $\left(\mathbf{c}, \mathbf{c}^{\prime}\right)$ sides of the cranium.

MCI yielded values of 0.426 for the ventral and 0.441 for the dorsal side of the cranium, indicating the absence of convergence, while for the mandible, a convergence pattern with the MCI value of 1.541-well above one-and above 95\% of the random MCI distribution (Figure 6), was detected.

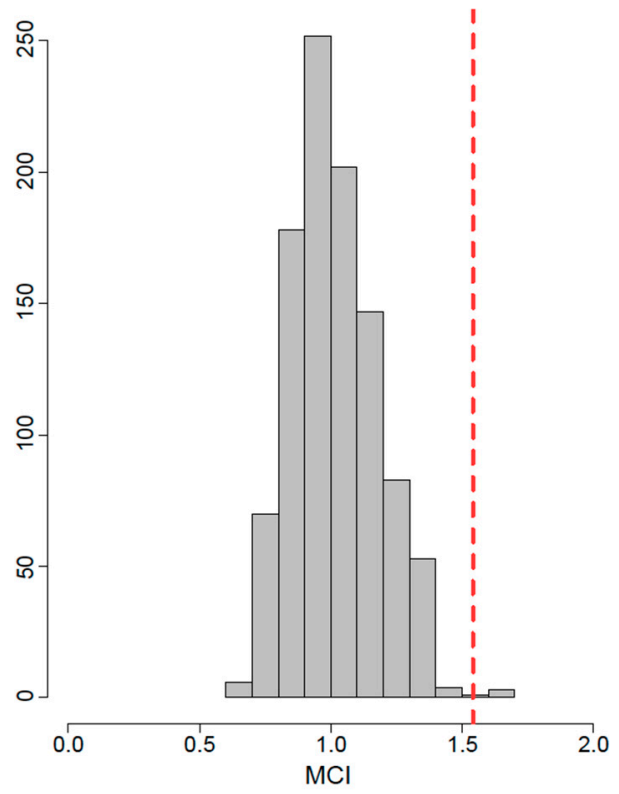

Figure 6. Multidimensional convergence index (MCI) of the sympatric and allopatric populations of both species obtained for the mandible (vertical dotted line) compared with a randomized distribution of MCI values. 


\subsection{Differences between the Two Hybrid Populations}

Captive and wild hybrids do not differ in shape, in relation to any of the structures analysed (Table 2), though wild hybrids have a larger ventral side of the cranium than their captive counterparts (Figure 3). Neighbour-joining networks reveal closer proximity of the hybrids to the allopatric populations of the two species where data for the ventral side of the skull are concerned, as well as the mandible (Figure $5 a, b)$. In relation to the dorsal side of the cranium, hybrids are seen to cluster between the two parent species (Figure 5c).

Table 2. Test of differences between captive and wild hybrids. Differences in shape and size were tested using MANOVA and Wilcoxon's tests, respectively, for the ventral and dorsal sides of the cranium and the mandible. P: $p$-value, numDf and denDf: Numerator and denominator degree of freedom. Cross-validation percentages (CVP) are provided as the mean and the $90 \%$ confidence interval (CI) of the distribution.

\begin{tabular}{|c|c|c|c|c|c|c|}
\hline \multirow{2}{*}{ Trait } & \multicolumn{2}{|c|}{ Mandible } & \multicolumn{2}{|c|}{ Ventral } & \multicolumn{2}{|c|}{ Dorsal } \\
\hline & Tests & CVP & Tests & CVP & Tests & CVP \\
\hline Shape & $\begin{array}{c}\mathrm{F}(2,12)=0.6 \\
p=0.56\end{array}$ & - & $\begin{array}{c}\mathrm{F}(2,12)=2.8 \\
p=0.09\end{array}$ & - & $\begin{array}{c}\mathrm{F}(10,4)=4.08 \\
p=0.09\end{array}$ & - \\
\hline Size & $\begin{array}{l}W=46 \\
p=0.04\end{array}$ & $\begin{array}{c}73.9 \% \\
(64.3-85.7 \%)\end{array}$ & $\begin{array}{c}W=52 \\
p=0.004\end{array}$ & $\begin{array}{c}79.4 \% \\
(71.4-92.9 \%)\end{array}$ & $\begin{array}{l}W=40 \\
p=0.19\end{array}$ & - \\
\hline
\end{tabular}

\subsection{Geographical Structure}

Unlike in the case of the dorsal side of the skull-for which no geographical structure could be detected, data for the ventral side and the mandible are seen to vary geographically (Table 3), with differences between the two species noted. The population of E. europaeus shows a geographical structure, as regards data on mandibular shape, while specimens of E. roumanicus also vary geographically in this respect, as well as in the size and shape of the ventral cranial side. However, the sampling on this remains limited and this conclusion is awaiting better support.

Table 3. Geographic structure of the data. Results of Mantel tests for shape and regression for size for ventral and dorsal sides of the cranium and the mandible.

\begin{tabular}{ccccccccc}
\hline \multirow{2}{*}{ Trait } & \multicolumn{4}{c}{ E. europaeus } & \multicolumn{4}{c}{ E. roumanicus } \\
\cline { 2 - 9 } & obs & $\boldsymbol{p}$-Value & adj. R2 & $\boldsymbol{p}$-value & obs & $\boldsymbol{p}$-Value & adj. R2 & $\boldsymbol{p}$-Value \\
\hline Mandible & 0.283 & 0.036 & 0.167 & 0.039 & 0.221 & 0.005 & 0.274 & 0.011 \\
Ventral & -0.09 & 0.775 & 0.04 & 0.232 & -0.066 & 0.762 & 0.18 & 0.042 \\
Dorsal & -0.070 & 0.626 & -0.01 & 0.44 & -0.014 & 0.53 & -0.02 & 0.47 \\
\hline
\end{tabular}

\section{Discussion}

\subsection{Convergent Character Displacement in Size and Shape}

Our first-ever reference to high-resolution three-dimensional geometric morphometrics in the case of hedgehogs helped reveal fine-scale differences between the two species in allopatry, while showing surprising similarity in circumstances of sympatry. Where matters of size are concerned, specimens of E. europaeus allopatric from E. roumanicus have larger crania and mandibles. In contrast, when present sympatrically, populations of the two species show a similar reduction in size, resulting in a much greater overlap than in allopatry, to the extent that cross-validation percentages are always lower in sympatric situations.

As regards shape, marked differences were detected for both species, between allopatric and sympatric populations. It emerged that most of the shape variation is clustered by allopatric/sympatric differences in ventral skull shape, as well as mandibles; while data for dorsal skull shape appear 
to be structured primarily by reference to inter-species differences. The overlap in the mandible variation, characterising sympatric populations in the discriminant analysis (Figure 4) confirmed by: their close proximity on the network (Figure 5); their lower percentage in cross-validation than their allopatric counterparts (Table 1); and the high MCI value, can be interpreted as a case of convergence in line with the pattern-based definition (Stayton 2015). However, interpretation of these results in accordance with the process-based definition of convergence (i.e., as bilateral convergent character-displacement) requires the examination of possible microevolutionary factors responsible for the presence of more-unified phenotypic traits under circumstances of sympatry.

\subsection{Hybridisation and Introgression}

Hybridisation might be the simplest explanation for the observed patterns, with hybrids in this case known to be large, and more similar in size to E. europaeus (perhaps as a reflection of the genome dominance of this species when it comes to the determination of size; or else in line with asymmetry in the ability to produce back-crosses). The experiments of Poduschka and Poduschka [41], combined with our data, suggest that asymmetrical introgression is to be anticipated (and therefore also asymmetrical changes in morphology).

In terms of shape, hybrids fall between the two parental allopatric morphologies when it comes to mandibles, and the ventral side of the skull. This is consistent with the renewal of the plesiomorphic state in hybrids. Interestingly, as captive and wild hybrids do not differ in skull shape (while the former have larger crania and mandibles than their wild counterparts), the suggestion is that populations held in isolation may develop different morphological traits [42,43].

Although past introgression events may have had a role to play in hedgehogs [4], the recent level of hybridisation is very low [3,5]. However, a genomic approach and ascertainment of the level of ancient introgression will be necessary if the potential role of hybridisation in phenotypic evolution is to be investigated fully.

\subsection{Clinal Variation}

A second potential explanation would involve general trends to the clinal variation characteristics of both species, possibly affected by the same selective environmental gradient that overrides the effect of competition [44]. However, given the limited width of the contact zone between the hedgehog species, it is difficult to imagine a longitudinal gradient taking on extreme values in central Europe. For example, Škoudlín [45] measured 23 metric characters and four proportional indices related to the skull, in order to compare specimens of E. roumanicus from the Czech Republic, Poland and Belarus. Those from Poland and Belarus were characterised by higher values for a majority of the characters studied, but the latitudinal pattern was rather in line with Bergmann's rule. A longitudinal cline has never been referred to in hedgehogs.

\subsection{Ecological Species Interactions-Competitive and Predator Pressure}

A third hypothesis would involve biotic ecological interactions, i.e., competitive pressure, as a possible causal factor accounting for patterns observed. The general expectation of divergent character displacement is based on a presumption of sufficiently narrow ecological valence, with resource competition generating selective pressure intense enough to promote niche diversification. It is well known that much of the diversity among terrestrial vertebrate skulls is associated with feeding $[6,46,47]$ and that the adaptive evolution associated with it can be rapid [48-50]. Hedgehogs are medium-sized plantigrade mammals whose low basal metabolic rates and related defensive anti-predator strategies reflect energetic constraints associated with the unpredictable distribution of resources and predation [51]. Therefore, when two hedgehog species form a sympatric zone, potentially characterised by higher population density than in allopatry, the resulting guild may approach the carrying capacity of the environment, with competition for resources generating a convergent reduction in body size, rather than divergent character displacement. This explanation is 
also consistent with convergence in the mandible shape. As the function of the lower jaw connects mainly with feeding $[47,52]$, in contrast to the cranium reflecting additional functions related to sensory organs and the brain [53,54], it is reasonable to ascribe respective patterns to evolutionary forces within the trophic niche. We hypothesize that decrease in size and convergence in shape is a result of local adaptations to overlapping dietary resources in the two species, and hence an example of convergent character displacement.

Background mechanisms underpinning the observed patterns could also act at the community level and entail predator pressure. The disruptive selection this causes could be seen as a proximate mechanism behind a bimodal distribution of body size in mammals, in line with Cope's rule [55]. Mammals filling "the mid-size gap" often possess defensive weaponry apomorphies, such as the spines in hedgehogs [56], thereby pointing to the major evolutionary consequences of predation among such medium-sized mammals. Recent ecological research on hedgehogs also reported a marked effect of intraguild predation [57]. The associated hypothesis accounting for our results would therefore involve higher predator pressure in the sympatric zone, as a reflection of the higher population density among hedgehogs in general, and the recent mesopredator release [58], i.e., population increases in e.g., red foxes and European badgers in central Europe. That may in turn reflect the population declines that characterised large carnivores for a long period in the past. All of this leaves evolution in the direction of smaller body size in prey species as more suitable for achieving crypsis. These ecological mechanisms could all be facilitated by such anthropogenic changes in the environment as declines in numbers of invertebrates due to the use of pesticides, fragmentation of habitats, or increased traffic.

As detailed knowledge about ecological niche of hedgehogs is crucial in understanding their population decline [59] and proposing rational conservation management, we propound further attention to described phenomena. Considering the substantial regional variation and steep east-west gradients in socioeconomic variables in Europe, resulting in geographic patterns in landscape fragmentation [60] and anthropogenic pressure on ecosystems and hedgehog populations, as well as differences in conservation management in rescue centers [61], large-scale studies using a standardized methodology are needed to compensate for possible observation bias and investigate more closely the complex phenotypic variation patterns and ecological niche characteristics. Taking into account environmental variables will also allow for the study of the presence of complex phenomena caused by selection pressures related to urbanization, the development of industrialised agriculture and other human-mediated factors such as anthropogenic dwarfing of species.

\section{Conclusions}

In the present study, seldom observed sympatric character displacement was ascertained in the contact zone of two sympatric hedgehog species in central Europe based on the analysis of skull size and shape. Considering almost complete formation of reproductive isolating barriers, we presume hybridisation and introgression are not the major processes behind the observed pattern. We hypothesise that unidirectional selection to size and shape related to competition in the trophic niche is responsible for that pattern, and that size changes of the skull could also be facilitated by a reduction in body size related to selection pressures, mediated by the Anthropocene mesopredator release.

Supplementary Materials: The following are available online at http://www.mdpi.com/2076-2615/10/10/1803/s1, Table S1: Samples used in the study, Table S2: Landmark coordinates, Figure S1: Cranial and mandibular shape differences.

Author Contributions: B.Č.B. and P.H. conceived and designed the study; B.Č.B. and M.R.K. collected and prepared the specimens for analyses; M.R.K. made morphometric measurements under the supervision of W.B. and A.S.-J. A.E. analysed the morphometric data; M.L. contributed to genetic characterization of the samples; B.Č.B., A.E., M.R.K., W.B. and P.H. drafted the manuscript and all authors contributed to the final version. All authors have read and agreed to the published version of the manuscript.

Funding: This study was funded by the Grant Agency of Charles University (GAUK 538218) and the Grant Agency of Czech University of Life Sciences Prague (IGA 20205007 and CIGA 20185006). MRK was supported by the Charles University Research Centre program No. 204069. 
Acknowledgments: We would like to thank the Museum für Naturkunde, Berlin (Germany) and the Institute of Vertebrate Biology, Brno (Czech Republic) for a loan of the skulls. We also thank the rescue centers in the Czech Republic, namely Vlašim, Praha, Bruntál, Jaroměř and Litoměřice, for their contribution to the study. For valuable suggestions we thank to Dr. Vladimír Vohralík.

Conflicts of Interest: The authors declare no conflict of interest.

\section{References}

1. Hewitt, G.M. Post-Glacial Re-Colonization of European Biota. Biol. J. Linn. Soc. 1999, 68, 87-112. [CrossRef]

2. Seddon, J.M.; Santucci, F.; Reeve, N.J.; Hewitt, G.M. DNA Footprints of European Hedgehogs, Erinaceus europaeus and E. concolor: Pleistocene Refugia, Postglacial Expansion and Colonization Routes. Mol. Ecol. 2001, 10, 2187-2198. [CrossRef] [PubMed]

3. Bolfíková, B.; Hulva, P. Microevolution of Sympatry: Landscape Genetics of Hedgehogs Erinaceus europaeus and E. roumanicus in Central Europe. Heredity 2012, 108, 248-255. [CrossRef] [PubMed]

4. Černá Bolfíková, B.; Eliášová, K.; Loudová, M.; Kryštufek, B.; Lymberakis, P.; Sándor, A.D.; Hulva, P. Glacial Allopatry vs. Postglacial Parapatry and Peripatry: The Case of Hedgehogs. PeerJ 2017, 5, e3163:1-e3163:21. [CrossRef]

5. Curto, M.; Winter, S.; Seiter, A.; Schmid, L.; Scheicher, K.; Barthel, L.M.F.; Plass, J.; Meimberg, H. Application of a SSR-GBS Marker System on Investigation of European Hedgehog Species and Their Hybrid Zone Dynamics. Ecol. Evol. 2019, 9, 2814-2832. [CrossRef]

6. Evin, A.; Horáček, I.; Hulva, P. Phenotypic Diversification and Island Evolution of Pipistrelle Bats (Pipistrellus pipistrellus Group) in the Mediterranean Region Inferred from Geometric Morphometrics and Molecular Phylogenetics. J. Biogeogr. 2011, 38, 2091-2105. [CrossRef]

7. Coyne, J.; Orr, H. Speciation; Sinauer Associates: Sunderland, MA, USA, 2004.

8. Reifová, R.; Reif, J.; Antczak, M.; Nachman, M.W. Ecological Character Displacement in the Face of Gene Flow: Evidence from Two Species of Nightingales. BMC Evol. Biol. 2011, 11, 138:1-138:11. [CrossRef]

9. Kryštufek, B.; Tvrtković, N.; Paunović, M.; Özkan, B. Size Variation in the Northern White-Breasted Hedgehog Erinaceus roumanicus: Latitudinal Cline and the Island Rule. Mammalia 2009, 73, 299-306. [CrossRef]

10. Reeve, N. Hedgehogs; T \& AD Poyser: London, UK, 1994.

11. Ruprecht, A. Correlation Structure of Skull Dimensions in European Hedgehogs. Acta Theriol. 1972, 17, 419-442. [CrossRef]

12. Holz, H.; Niethammer, J. Erianceus concolor Martin, 1838-Weissbrustigel, Ostigel. In Handbuch der Säugetiere Europas 3/1; Niethammer, J., Krapp, F., Eds.; Aula-Verlag: Wiesbaden, Germany, 1990; pp. 50-64.

13. Holz, H.; Niethammer, J. Erinaceus europaeus Linnaeus, 1758-Braunbrustigel, Westigel. In Handbuch der Säugetiere Europas 3/1; Niethammer, J., Krapp, F., Eds.; Aula-Verlag: Wiesbaden, Germany, 1990; pp. $26-49$.

14. Kryštufek, B. Cranial Variability in the Eastern Hedgehog Erinaceus concolor (Mammalia: Insectivora). J. Zool. 2002, 258, 365-373. [CrossRef]

15. Hrabě, V. Variation in Cranial Measurement of Erinaceus concolor roumanicus (Insectivora, Mammalia). Zool. List. 1976, 25, 315-326.

16. Niethammer, J.; Krapp, F. Handbuch Der Säugetiere Europas. Bd. 3/1, Insektenfresser-Insectivora, Herrentiere-Primates; Niethammer, J., Krapp, F., Eds.; Aula-Verlag: Wiesbaden, Germany, 1990.

17. Hrabě, V. Variation in Somatic Characters of Two Species of Erinaceus (Insectivora, Mammalia) in Relation to Individual Age. Zool. List. 1975, 24, 335-351.

18. Wolff, P. Unterscheidungsmerkmale am Unterkiefer von Erinaceus europaeus L. und Erinaceus concolor Martin. Ann. Naturhist. Mus. Wien 1976, 80, 337-341. [CrossRef]

19. Kratochvíl, J. Die Hirnmasse Der Mitteleuropäischen Arten Der Gattung Erinaceus (Insectivora, Mamm.). Folia Zool. 1980, 29, 1-20.

20. Hrabě, V. Notes on the Dentition of Two Erinaceus Spp. from Czechoslovakia (Insectivora, Mammalia). Folia Zool. 1981, 30, 311-316.

21. Hanken, J.; Hall, B.K. The Skull, Volume 3: Functional and Evolutionary Mechanisms; University of Chicago Press: Chicago, IL, USA, 1993.

22. Škoudlín, J. Zur Altersbestimmung Bei Erinaceus europaeus Und Erinaceus concolor (Insectivora: Erinaceidae). Věst. Českosl. Spol. Zool. 1976, 40, 300-306. 
23. Herter, K. Studien Zur Verbreitung Der Europäischen Igel. Arch. Naturgesch. 1934, 3, 21-382.

24. Rohlf, F.J.; Slice, D. Extensions of the Procrustes Method for the Optimal Superimposition of Landmarks. Syst. Zool. 1990, 39, 40-59. [CrossRef]

25. Goodall, C.R. Procrustes Methods in the Statistical Analysis of Shape Revisited. In Current Issues in Statistical Shape Analysis; Mardia, K.V., Gill, C.A., Eds.; Leeds University Press: Leeds, UK, 1995; pp. 18-33.

26. Bookstein, F. Morphometric Tools for Landmark Data: Geometry and Biology; Cambridge University Press: New York, NY, USA, 1991. [CrossRef]

27. Evin, A.; Cucchi, T.; Cardini, A.; Strand Vidarsdottir, U.; Larson, G.; Dobney, K. The Long and Winding Road: Identifying Pig Domestication through Molar Size and Shape. J. Archaeol. Sci. 2013, 40, 735-743. [CrossRef]

28. Monteiro, L.R. Multivariate Regression Models and Geometric Morphometrics: The Search for Causal Factors in the Analysis of Shape. Syst. Biol. 1999, 48, 192-199. [CrossRef]

29. Schlager, S. Morpho and Rvcg-Shape Analysis in R. In Statistical Shape and Deformation Analysis: Methods, Implementation and Applications; Zheng, G., Li, S., Szekely, G., Eds.; Academic Press: San Diego, CA, USA, 2017; pp. 217-256.

30. Baylac, M.; Frieß, M. Fourier Descriptors, Procrustes Superimposition, and Data Dimensionality: An Example of Cranial Shape Analysis in Modern Human Populations. In Modern Morphometrics in Physical Anthropology; Slice, D.E., Ed.; Springer: Boston, MA, USA, 2005; pp. 145-162. [CrossRef]

31. Benjamini, Y.; Hochberg, Y. Controlling the False Discovery Rate: A Practical and Powerful Approach to Multiple Testing. J. R. Stat. Soc. Ser. B 1995, 57, 289-300. [CrossRef]

32. Mahalanobis, P. On the Generalized Distance in Statistics. Proc. Natl. Acad. Sci. India 1936, 2, 49-55.

33. Mantel, N. The Detection of Disease Clustering and a Generalized Regression Approach. Cancer Res. 1967, 27, 209-220. [PubMed]

34. Sokal, R.R.; Rohlf, F.J. Biometry: The Principles and Practice of Statistics in Biological Research, 3rd ed.; W.H. Freeman and Co.: New York, NY, USA, 1995.

35. Stayton, C.T. The Definition, Recognition, and Interpretation of Convergent Evolution, and Two New Measures for Quantifying and Assessing the Significance of Convergence. Evolution 2015, 69, 2140-2153. [CrossRef] [PubMed]

36. Stayton, C.T. Testing Hypotheses of Convergence with Multivariate Data: Morphological and Functional Convergence among Herbivorous Lizards. Evolution 2006, 60, 824-841. [CrossRef]

37. Zelditch, M.L.; Swiderski, D.L.; Sheets, H.D. Geometric Morphometrics for Biologists: A Primer, 2nd ed.; Elsevier, Academic Press: Amsterdam, The Netherlands, 2012.

38. Adams, D.; Collyer, M.; Kaliontzopoulou, A.; Sherratt, E. Geomorph: Software for Geometric Morphometric Analyses. R Package Version 3.1.0. 2019. Available online: https:/github.com/geomorphR/geomorph (accessed on 20 December 2019).

39. Dray, S.; Dufour, A.-B. The Ade4 Package: Implementing the Duality Diagram for Ecologists. J. Stat. Softw. 2007, 22, 1-20. [CrossRef]

40. R Core Team. R: A Language and Environment for Statistical Computing. R Foundation for Statistical Computing. 2020. Available online: https://www.r-project.org (accessed on 29 February 2020).

41. Poduschka, W.; Poduschka, C. Kreuzungsversuche an Mitteleuropäischen Igeln. Säugetierk. Mitt. 1983, 31, 1-12.

42. O'Regan, H.J.; Kitchener, A.C. The Effects of Captivity on the Morphology of Captive, Domesticated and Feral Mammals. Mamm. Rev. 2005, 35, 215-230. [CrossRef]

43. Evin, A.; Dobney, K.; Schafberg, R.; Owen, J.; Strand Vidarsdottir, U.; Larson, G.; Cucchi, T. Phenotype and Animal Domestication: A Study of Dental Variation between Domestic, Wild, Captive, Hybrid and Insular Sus scrofa. BMC Evol. Biol. 2015, 15, 6. [CrossRef]

44. Meiri, S.; Simberloff, D.; Dayan, T. Community-Wide Character Displacement in the Presence of Clines: A Test of Holarctic Weasel Guilds. J. Anim. Ecol. 2011, 80, 824-834. [CrossRef]

45. Škoudlín, J. Craniometric Analysis of a Czechoslovak and a Polish Population of Erinaceus concolor (Mammalia: Erinaceidae). Věst. Českosl. Spol. Zool. 1982, 46, 304-316.

46. Smith, K.K. The Form of the Feeding Apparatus in Terrestrial Vertebrates: Studies of Adaptation and Constraint. In The Skull; Hanken, J., Hall, B.K., Eds.; University of Chicago Press: Chicago, IL, USA, 1993; pp. 150-196. 
47. Zelditch, M.L.; Ye, J.; Mitchell, J.S.; Swiderski, D.L. Rare Ecomorphological Convergence on a Complex Adaptive Landscape: Body Size and Diet Mediate Evolution of Jaw Shape in Squirrels (Sciuridae). Evolution 2017, 71, 633-649. [CrossRef] [PubMed]

48. Hendry, A.P.; Kinnison, M.T. Perspective: The Pace of Modern Life: Measuring Rates of Contemporary Microevolution. Evolution 1999, 53, 1637-1653. [CrossRef] [PubMed]

49. Carroll, S.P.; Hendry, A.P.; Reznick, D.N.; Fox, C.W. Evolution on Ecological Time-Scales. Funct. Ecol. 2007, 21, 387-393. [CrossRef]

50. Herrel, A.; Huyghe, K.; Vanhooydonck, B.; Backeljau, T.; Breugelmans, K.; Grbac, I.; Van Damme, R.; Irschick, D.J. Rapid Large-Scale Evolutionary Divergence in Morphology and Performance Associated with Exploitation of a Different Dietary Resource. Proc. Natl. Acad. Sci. USA 2008, 105, 4792-4795. [CrossRef]

51. Lovegrove, B.G. The Evolution of Body Armor in Mammals: Plantigrade Constraints of Large Body Size. Evolution 2001, 55, 1464-1473. [CrossRef]

52. Morris, P.J.R.; Cobb, S.N.F.; Cox, P.G. Convergent Evolution in the Euarchontoglires. Biol. Lett. 2018, 14, 20180366:1-20180366:4. [CrossRef]

53. Cheverud, J.M. Phenotypic, Genetic, and Environmental Morphological Integration in the Cranium. Evolution 1982, 36, 499-516. [CrossRef]

54. Goswami, A. Cranial Modularity Shifts during Mammalian Evolution. Am. Nat. 2006, 168, $270-280$. [CrossRef]

55. Alroy, J. Cope's Rule and the Dynamics of Body Mass Evolution in North American Fossil Mammals. Science 1998, 280, 731-734. [CrossRef]

56. Stankowich, T.; Campbell, L.A. Living in the Danger Zone: Exposure to Predators and the Evolution of Spines and Body Armor in Mammals. Evolution 2016, 70, 1501-1511. [CrossRef] [PubMed]

57. Williams, B.M.; Baker, P.J.; Thomas, E.; Wilson, G.; Judge, J.; Yarnell, R.W. Reduced Occupancy of Hedgehogs (Erinaceus europaeus) in Rural England and Wales: The Influence of Habitat and an Asymmetric Intra-Guild Predator. Sci. Rep. 2018, 8, 1-10. [CrossRef] [PubMed]

58. Ritchie, E.G.; Johnson, C.N. Predator interactions, mesopredator release and biodiversity conservation. Ecol. Lett. 2009, 12, 982-998. [CrossRef] [PubMed]

59. Hof, A.R.; Bright, P.W. Quantifying the Long-Term Decline of the West European Hedgehog in England by Subsampling Citizen-Science Datasets. Eur. J. Wildl. Res. 2016, 62, 407-413. [CrossRef]

60. Hulva, P.; Černá Bolfíková, B.; Woznicová, V.; Jindřichová, M.; Benešová, M.; Mysłajek, R.W.; Nowak, S.; Szewczyk, M.; Niedźwiecka, N.; Figura, M.; et al. Wolves at the Crossroad: Fission-Fusion Range Biogeography in the Western Carpathians and Central Europe. Divers. Distrib. 2018, 24, 179-192. [CrossRef]

61. Ploi, K.; Curto, M.; Bolfíková, B.Č.; Loudová, M.; Hulva, P.; Seiter, A.; Fuhrmann, M.; Winter, S.; Meimberg, H. Evaluating the Impact of Wildlife Shelter Management on the Genetic Diversity of Erinaceus europaeus and E. roumanicus in Their Contact Zone. Animals 2020, 10, 1452. [CrossRef]

(C) 2020 by the authors. Licensee MDPI, Basel, Switzerland. This article is an open access article distributed under the terms and conditions of the Creative Commons Attribution (CC BY) license (http://creativecommons.org/licenses/by/4.0/). 